\title{
Produtividade da cultura da batata-doce em diferentes sistemas de preparo do solo
}

\author{
Amarílis Beraldo Rós $\left({ }^{1 *}\right)$; João Tavares Filho $\left({ }^{2}\right)$; Graziela Moraes de Cesare Barbosa ( ${ }^{3}$ ) \\ (1) Agência Paulista de Tecnologia dos Agronegócios (APTA), Polo Alta Sorocabana, 19015-970 Presidente Prudente (SP), Brasil. \\ (2) Universidade Estadual de Londrina (UEL), Departamento de Agronomia, 86051-980 Londrina (PR), Brasil. \\ (3) Instituto Agronômico do Parará (IAPAR), 86047-902 Londrina (PR), Brasil. \\ (*) Autora correspondente: amarilis@apta.sp.gov.br
}

Recebido: 20/mar./2013; Aceito: 7/jun./2013

\section{Resumo}

Trabalhos sobre preparo reduzido em solos cultivados com raízes e tubérculos são escassos e controversos. Este trabalho objetivou avaliar e comparar a produtividade de raízes tuberosas de plantas de batata-doce cultivadas em argissolo vermelho-amarelo sob preparo convencional (aração seguida de gradagem niveladora e posterior levantamento de leiras com sulcador) e sob preparo reduzido com manutenção de palhada superficial (sem revolvimento do solo, exceto nas linhas de plantio). O delineamento experimental foi em blocos ao acaso, em esquema de parcelas subdivididas. As parcelas principais corresponderam aos tratamentos preparo convencional (com confecção de leiras) e preparo reduzido, e as subparcelas, às quatro épocas de coleta: 90, 120, 150 e 180 dias após plantio. Foram avaliadas as características: produtividades total e comercial, números de raízes tuberosas total e comercial, e massa de matéria fresca individual média das raízes tuberosas consideradas comerciais. A cultura da batata-doce apresentou produtividades total e comercial de raízes tuberosas 68 e 75\% superiores no plantio convencional, respectivamente, em relação ao preparo reduzido, em função de maiores números total e comercial de raízes tuberosas em solo preparado de maneira convencional. Não houve diferença entre os manejos de solo quanto à massa de matéria fresca individual de raízes tuberosas. Concluindo, o preparo convencional do solo é mais adequado ao cultivo da batata-doce.

Palavras-chave: Ipomoea batatas, conservação do solo, preparo reduzido, raiz tuberosa.

\section{Sweet potato yield under different soil managements}

\section{Abstract}

Studies about reduced tillage in soil cultivated with roots and tubers are rare and controversial. This study aimed to assess and compare the sweet potato tuberous roots yield in an alfisol type soil managed with conventional tillage (plowing followed by leveling and making mounds) and reduced tillage with straw on the soil surface (cultivated only along the rows). The experimental design was in randomized blocks in split-plot scheme. The principal plots corresponded to conventional tillage (with mounds) and reduced tillage, and the subplots to four collect periods: 90, 120, 150 and 180 days after planting. The characteristics evaluated were: total and commercial yields, numbers of total and commercial tuberous roots, and commercial tuberous roots individual fresh mass. Sweet potato crop had total and commercial tuberous roots yields around 68 and $75 \%$ higher in conventional tillage, respectively, than in reduced tillage. This response was caused by the high numbers of total and commercial roots in soil under conventional tillage. There was no difference between the soil management on tuberous roots individual fresh mass. As conclusion, the conventional tillage is better to the sweet potato crop.

Key words: Ipomoea batatas, soil conservation, reduced tillage, tuberous root.

\section{INTRODUÇÃO}

A cultura da batata-doce é produzida em todas as regiôes brasileiras e seu cultivo ocorre após intenso revolvimento do solo. Assim, o sistema de preparo de solo para o plantio da batata-doce é uma etapa com elevado potencial de degradação do solo e, consequentemente, de assoreamento de corpos d'água, fatores que, além da degradação ambiental, acentuam o empobrecimento de produtores rurais e de suas famílias.

Embora a batata-doce seja atualmente cultivada apenas em áreas sob preparo convencional de solo (aração e gradagem), BARRERA (1986) já recomendava seu plantio em sulco em solos arenosos, visto que a construção de leiras contribuía para a perda da umidade do solo, podendo-se formar os camalhôes durante as operaçôes de capina e amontoa. Além da perda de umidade do solo com o seu revolvimento, este é facilmente erodido durante as chuvas, principalmente na fase inicial de desenvolvimento das plantas. Por isso, o sistema de plantio direto sob palha tornou-se uma importante prática de manejo do solo, uma vez que diminui significativamente a perda do recurso por 
erosão hídrica e contribui para a manutenção da umidade no solo (Llanillo et al., 2006).

Portanto, práticas de manejo do solo que demandam menor revolvimento do mesmo e mantêm restos culturais na superfície têm suas propriedades bastante difundidas, como, por exemplo, a manutenção da fertilidade (Agbede, 2008) e da umidade na camada superficial do solo (FABrizZi et al., 2005; MARTORANo et al., 2009), mas estudos sobre cultivo de espécies vegetais cuja parte comercial é subterrânea em solos não revolvidos são escassos. Howeler et al. (1993), em um trabalho de revisão, verificaram que culturas de raízes e tubérculos são sensíveis à compactação do solo, à aeração inadequada ou à má drenagem e, deste modo, respondem favoravelmente ao sistema convencional de preparo do solo. Opinião que é compartilhada por autores de trabalhos com batata (FonTes et al., 2007; Ivany et al., 2007; Nunes et al., 2006) e mandioca (Oliveira et al., 2001; Pequeno et al., 2007).

Por outro lado, resultados a favor do preparo reduzido com essas culturas também são divulgados. Para Carter et al. (2009), Gordon et al. (2011) e Holmstrom et al. (2006) não há diferença de produtividade e de qualidade de batatas cultivadas em solo preparado convencionalmente e em solo com menor revolvimento. Alva et al. (2009) e Fernandes et al. (2006) complementam que, além da manutençáo de produtividade e qualidade de tubérculos de batata, o preparo reduzido do solo favorece a qualidade do solo e representa uma opçáo de economia de energia e custos. Em inhame, Oliveira et al. (2004) verificaram semelhantes produtividades de rizomas nos sistemas de plantios convencional e direto. Quanto à cultura da mandioca, Отsuвo et al. (2008) relataram incremento de produtividade de raízes em solo sob cultivo mínimo sobre restos culturais de milheto em relação ao convencionalmente preparado. AiYelari et al. (2001) inclusive destacaram a viabilidade da produção de mandioca em sistema de preparo reduzido.

Assim, considerando-se a hipótese de que a cultura da batata-doce pode apresentar elevada produtividade de raízes tuberosas em solo sob preparo reduzido, objetivou-se com este trabalho avaliar e comparar as produtividades de raízes tuberosas de plantas de batata-doce cultivadas em argissolo vermelho-amarelo preparado convencionalmente e sob preparo reduzido e estabelecer comparaçôes entre elas.

\section{MATERIAL E MÉTODOS}

O trabalho foi conduzido em Presidente Prudente (SP), $22^{\circ} 11^{\prime} \mathrm{S}, 51^{\circ} 23^{\prime} \mathrm{W}$ e $424,3 \mathrm{~m}$ de altitude, de março de 2009 a abril de 2010, em um argissolo vermelho-amarelo, com relevo suave ondulado, declive médio de $7 \%$. Foi realizada amostragem de solo na área sob preparo reduzido no momento do plantio da batata-doce para determinaçáo de atributos químicos e granulometria, com os seguintes resultados para as camadas de $0,0-0,15$ e $0,15-0,30 \mathrm{~m}$ de profundidade: $\mathrm{pH}\left(\mathrm{CaCl}_{2} 1,0 \mathrm{~mol} \mathrm{~L}^{-1}\right) 5,3$ e 4,8; 43,3 e 50,8 $\mathrm{mg} \mathrm{dm}^{-3} \mathrm{de}_{\text {Mehlich }}$; 6,7 e 3,93 $\mathrm{g} \mathrm{dm}^{-3} \mathrm{de} \mathrm{C;} \mathrm{2,94} \mathrm{e}$ $3,42 \mathrm{cmol}_{c} \mathrm{dm}^{-3} \mathrm{de} \mathrm{H}+\mathrm{Al} ; 0,3$ e $0,33 \mathrm{cmol}_{c} \mathrm{dm}^{-3} \mathrm{de} \mathrm{K} ; 1,5$ e 0,97 $\mathrm{cmol}_{\mathrm{c}} \mathrm{dm}^{-3} \mathrm{de} \mathrm{Ca}$; 1,23 e 0,65 $\mathrm{cmol}_{\mathrm{c}} \mathrm{dm}^{-3} \mathrm{de} \mathrm{Mg}$; 50,75 e $36,31 \%$ de saturação por bases; 920 e $930 \mathrm{~g} \mathrm{~kg}^{-1}$ de areia; 30 e $20 \mathrm{~g} \mathrm{~kg}^{-1}$ de silte; 50 e $50 \mathrm{~g} \mathrm{~kg}^{-1}$ de argila, respectivamente.

O clima local é classificado como Aw (segundo classificação de Köppen), apresentando duas estaçôes bem definidas: verão quente e úmido e inverno ameno e seco; no entanto, não foi realizada irrigação durante o período de condução do experimento. Os valores da precipitação pluvial e das temperaturas médias mensais do ar observadas durante o período do experimento são apresentadas na figura 1 .

A área experimental vinha sendo ocupada por pastagem perene de Brachiaria decumbens não pastejada há mais de cinco anos. A pastagem foi dessecada por meio do uso de glifosato para a instalação de milho safrinha, cultura destinada à sistematização da área experimental. $\mathrm{O}$ milho foi semeado em plantio direto sob palha, densidade de 45.000 plantas ha $^{-1}$, em março de 2009.

Em outubro de 2009, as plantas secas de milho foram roçadas para a instalaçáo do experimento cujo delineamento experimental foi em blocos ao acaso, em esquema de parcelas subdivididas, com seis repetiçóes. As parcelas principais foram constituídas pelos tratamentos preparo convencional com confecção de leiras (PC) e preparo reduzido (PR), sendo que a palha da cultura do milho associada à palha dessecada de plantas de braquiária que emergiram do banco de sementes existente no solo no final do ciclo da cultura do milho (13.000 $\mathrm{kg} \mathrm{ha}^{-1}$ de matéria seca) promoveu cobertura do solo no sistema preparo reduzido e foi incorporada no sistema convencional. As subparcelas corresponderam a quatro épocas de coleta das raízes tuberosas de batata-doce: 90, 120, 150 e 180 dias após plantio (DAP) de ramas de batata-doce, variedade Londrina, sendo que

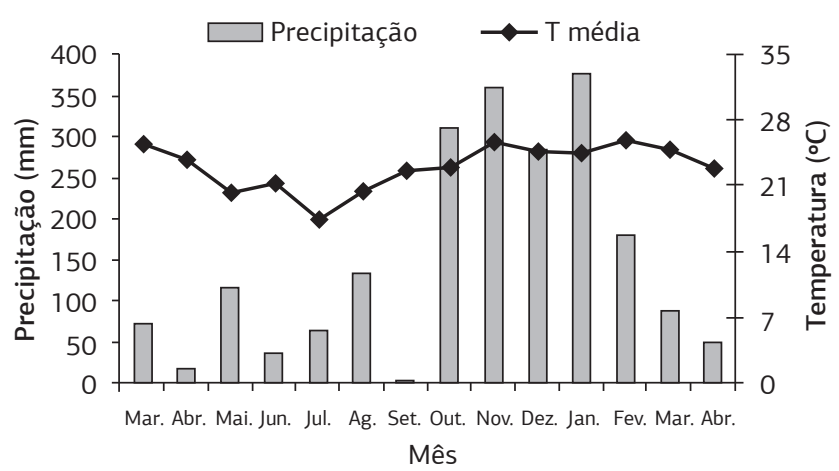

Figura 1. Precipitação pluvial e temperatura médias do ar observadas entre março de 2009 e abril de 2010, na localidade de Presidente Prudente (SP). 
a época de 180 DAP corresponde à época de colheita desta variedade para fins de consumo in natura.

O plantio convencional foi realizado por meio da utilizaçáo de aração com grade aradora, a uma profundidade entre 0,25 e $0,30 \mathrm{~m}$, seguida de gradagem niveladora, e posterior levantamento de leiras com sulcador (altura de aproximadamente $0,35 \pm 0,03 \mathrm{~m}$ ). No sistema de preparo reduzido houve movimentação do solo apenas nas linhas de plantio, as quais foram constituídas por sulcos abertos com uso de enxada.

Cada parcela experimental, com área total de $16,2 \mathrm{~m}^{2}$, foi constituída por três leiras/linhas distanciadas $0,9 \mathrm{~m}$ onde foram plantadas 20 ramas de $30 \mathrm{~cm}$ cada, oriundas de ponteiros de plantas de batata-doce, espaçadas a cada $0,3 \mathrm{~m}$, o que correspondeu a 37.000 plantas ha $^{-1}$. O plantio no sistema convencional foi realizado com abertura manual de orifícios com $0,08 \mathrm{~m}$ de profundidade, colocaçáo vertical da base da rama e enterrio também manual. Já no preparo reduzido foi aberto sulco de $0,08 \mathrm{~m}$ de profundidade por aproximadamente $0,10 \mathrm{~m}$ de largura por meio de uso de enxada, com posterior plantio da rama. A cobertura com solo da porçáo basal da rama também foi realizada por meio de enxada, tomando-se o cuidado de náo remover a palhada das entrelinhas. A área útil de cada parcela foi representada pelas 18 plantas centrais da leira do meio.

Foram avaliados as produtividades total e comercial e os números de raízes tuberosas total e comercial. Para produtividade total e número de raízes total foram consideradas todas as raízes tuberosas com massa igual ou superior a $40 \mathrm{~g}$, enquanto para a produtividade comercial e número de raízes comerciais foram consideradas as raízes tuberosas com massa de matéria fresca entre 80 e $1.000 \mathrm{~g}$ e bom aspecto (formato uniforme e liso). Também foi avaliada a massa de matéria fresca média individual das raízes tuberosas consideradas comerciais.

Os dados obtidos foram submetidos a análises de variância e as médias foram ajustadas a equaçóes de regressão polinomial. O critério para a escolha do modelo foi a significância pelo teste $\mathrm{F}$ a $5 \%$ de probabilidade de ocorrência do erro Tipo I e os maiores valores do coeficiente de determinação $\left(R^{2}\right)$.

\section{RESULTADOS E DISCUSSÃO}

Houve interação entre os tratamentos preparo de solo e épocas de coleta nas características produtividades total e comercial de raízes tuberosas de batata-doce. As produtividades total e comercial dos dois sistemas de preparo apresentaram resposta estimada segundo modelo linear, apresentando maiores valores com o aumento do período das plantas no campo (Figura 2). Tal fato está associado ao aumento da massa de matéria fresca individual das raízes tuberosas, visto que estas raízes acumulam maior quantidade de substâncias reservas em função do maior tempo de permanência no campo.
O preparo convencional foi responsável pelas maiores produtividades total e comercial da cultura, em relaçáo ao preparo reduzido, durante o período avaliado. A produtividade total estimada de raízes tuberosas no preparo convencional, aos 90 DAP, correspondeu a 15,6 t ha ${ }^{-1}$, enquanto a produtividade total estimada no preparo reduzido foi de $8,7 \mathrm{t} \mathrm{ha}^{-1}$. Quanto às produtividades comerciais nos sistemas preparo convencional e reduzido, os valores foram de 13,7 e 6,6 $\mathrm{t} \mathrm{ha}^{-1}$, respectivamente. Desse modo, o preparo reduzido acarretou menor armazenamento de substâncias reservas nas raízes tuberosas até esta fase, o que pode estar relacionado à maior densidade do solo e maior resistência à penetração de raízes em relação ao preparo convencional, conforme verificado por Rós et al. (2013) ao estudarem atributos físicos de argissolo vermelho-amarelo sob esses sistemas de preparo do solo para o cultivo da batata-doce. A maior densidade do solo no preparo reduzido pode promover restriçóes ao crescimento das raízes (tuberosas e de absorção) (WatanAbe et al., 2002) e à absorção de nutrientes pelas mesmas (QIN et al., 2005).

As produtividades totais estimadas, aos 180 DAP, atingiram 36,5 e $21,7 \mathrm{t} \mathrm{ha}^{-1}$, nos preparos convencional e reduzido, respectivamente, enquanto as produtividades estimadas comerciais foram de 34,5 e 19,7 $\mathrm{t} \mathrm{ha}^{-1}$, respectivamente. Essas informaçóes corroboram os trabalhos de Agbede (2010) e Anikwe e Ubochi (2007), os quais constataram que o plantio convencional resulta em maior produtividade de raízes tuberosas de batata-doce em relação ao plantio em solo não revolvido, contudo, a produtividade total no plantio convencional no trabalho de Agbede (2010) foi 30\% superior ao plantio direto, enquanto no presente trabalho o solo revolvido proporcionou acréscimo de $68 \%$ aos 180 DAP.

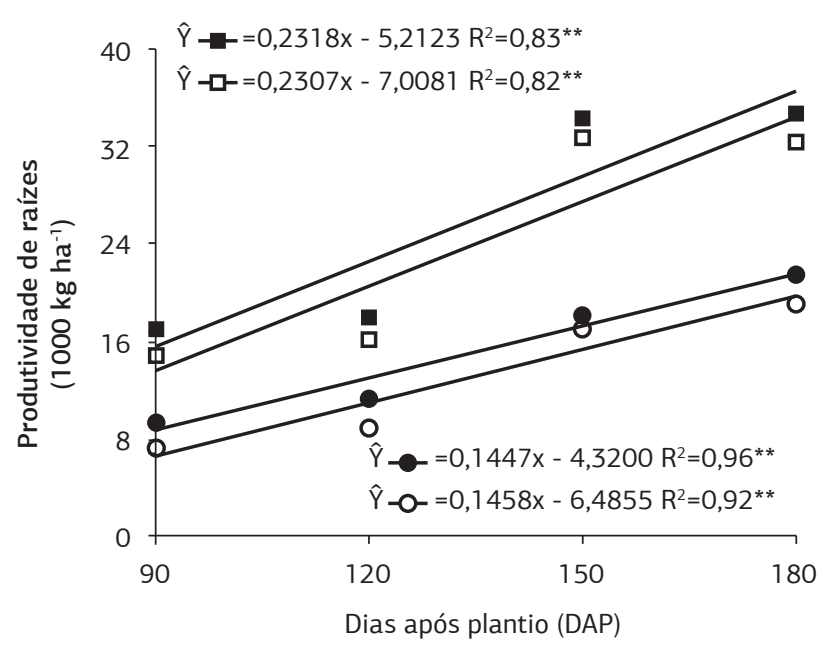

Figura 2. Produtividades total e comercial de raízes tuberosas de batata-doce em sistema convencional e preparo reduzido de solo. \#: produtividade total no sistema convencional de preparo do solo; $\square$ : produtividade comercial no sistema convencional de preparo do solo; •: produtividade total em preparo reduzido; e $\circ$ : produtividade comercial em preparo reduzido. ${ }^{* *} \mathrm{p}<0,01$. 
Resultados apresentados por Agbede e Adekiya (2009) também relatam maiores rendimentos da cultura da batata-doce em solos preparados convencionalmente, em relaçáo a solos não revolvidos, o que, segundo os autores, ocorre em função de o solo revolvido apresentar menor densidade e maior porosidade.

Odjugo (2008), em trabalho com a cultura da mandioca, descreve maiores rendimentos de raízes em solos onde houve revolvimento do solo, o que correspondeu a incremento de $46 \%$ em relaçáo ao plantio direto. Pequeno et al. (2007), em trabalho comparativo entre plantio convencional, cultivo mínimo e plantio direto, obtiveram maior produtividade de raízes de mandioca no sistema convencional, em latossolo vermelho de textura franco arenosa. A cultura do inhame também respondeu de maneira semelhante, apresentando maior produtividade de tubérculos em solos onde houve sua movimentação em relaçáo a solos não revolvidos (AgBede, 2006).

Anikwe e Uвоchi (2007) relatam que práticas de plantio direto apresentam vantagens sobre o plantio convencional, como maior conservação da umidade do solo, diminuição de sua temperatura, maiores teores de carbono orgânico e de $\mathrm{N}$ total. Mas, segundo esses autores, a característica menor densidade de solo preparado sob sistema convencional resulta em vantagens que se sobrepóem às características positivas do plantio direto, favorecendo a produtividade da cultura da batata-doce. De maneira semelhante, Oliveira et al. (2001) verificaram que preparo convencional e mínimo em nitossolo vermelho distrófico latossólico proporcionam condiçóes físicas de solo que permitem maior crescimento e produtividade de raízes de plantas de mandioca que o plantio direto.

No entanto, em taioba, AgBede (2008) verificou maior produtividade de rizomas em plantio direto em relação ao convencional, o que foi relacionado à maior umidade do solo quando náo revolvido. Em trabalho com a cultura da mandioca em solo com textura arenosa, Отьиво et al. (2008) verificaram a influência do sistema de manejo e do preparo do solo na produtividade da raiz, constatando que há incremento na produtividade ao se realizar o plantio das manivas em sistema de cultivo mínimo sobre restos culturais de milheto em comparação ao plantio após preparo convencional do solo. Em trabalho de Gabriel Filho et al. (2000) não houve diferença de produtividade de raízes de mandioca em sistema convencional e preparo mínimo.

Assim, são necessários mais estudos sobre a viabilidade do cultivo de batata-doce sob preparo reduzido do solo, visto que a prática do plantio direto em longo período de tempo favorece os atributos físicos do solo, tornando-os mais adequados ao desenvolvimento vegetal que o plantio convencional, conforme verificado por Tavares Filho et al. (2001), em latossolo vermelho argiloso, com plantio direto sendo realizado há mais de 20 anos.

Com relação ao número de raízes tuberosas, não houve efeito significativo entre as médias do número total de raízes nas diferentes épocas de coleta no preparo reduzido, ou seja, o número médio de raízes tuberosas foi considerado 82.400 unidades $\mathrm{ha}^{-1}$, em todas as épocas de coleta (Figura 3). O número de raízes comerciais no sistema de preparo reduzido apresentou comportamento segundo modelo linear crescente da primeira à última coleta, variando, em valores estimados, de 48.100 a 73.500 unidades ha-1 ${ }^{-1}$. No sistema de preparo convencional, os números total e comercial de raízes apresentaram resposta segundo modelo linear, cujos valores médios estimados variaram de 106.723 unidades ha $^{-1}$ aos 90 DAP a 154.045 unidades ha $\mathrm{h}^{-1}$ aos 180 DAP.

Comparando-se as duas formas de preparo de solo, verificou-se que o preparo reduzido com palha superficial foi desfavorável ao surgimento de raízes tuberosas. Verifica-se que a proporção entre número de raízes comerciais e número de raízes total no preparo reduzido foi inferior à mesma proporção no preparo convencional aos $90 \mathrm{DAP}$, ou seja, até essa época, no preparo reduzido, o acúmulo de substâncias reservas nas raízes tuberosas ocorreu de maneira mais lenta, ocasionando grande proporção de raízes com massa fresca inferior a $80 \mathrm{~g}$ (consideradas não comerciais). De acordo com AgBede (2006), em trabalho com inhame, a maior densidade do solo pode causar resistência mecânica à penetração de raízes e ao crescimento dos tubérculos, prejudicando a absorçáo de nutrientes e de água pela planta. Nunes et al. (2006) verificaram que batateiras apresentaram respostas positivas quanto ao teor de macronutrientes em seus órgãos e produtividade de tubérculos com o revolvimento do solo.

A média das massas frescas individuais das raízes tuberosas nos dois sistemas não apresentou diferença estatística (Figura 4). Tal fato enfatiza a influência do sistema de

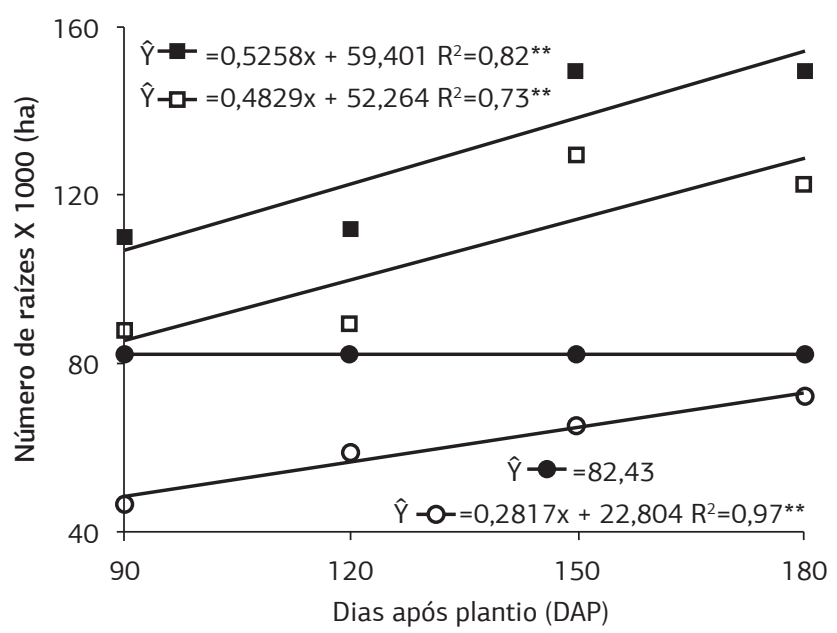

Figura 3. Números total e comercial de raízes tuberosas de batatadoce em sistema convencional de preparo de solo e preparo reduzido. n: número total de raízes tuberosas no sistema convencional de preparo do solo; $\square$ : número comercial de raízes tuberosas no sistema convencional de preparo do solo; $\bullet$ : número total de raízes tuberosas em preparo reduzido; e $\bigcirc$ : número comercial de raízes tuberosas em preparo reduzido. ${ }^{* *} \mathrm{p}<0,01$. 


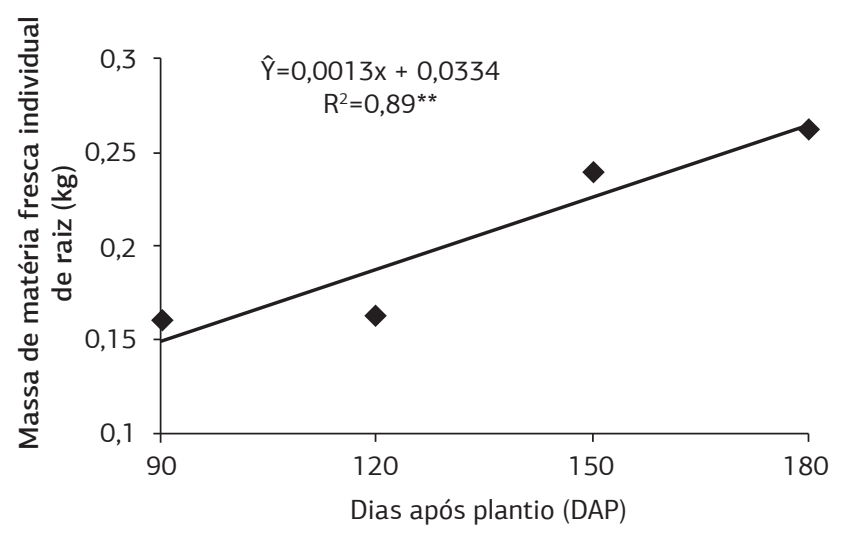

Figura 4. Massa de matéria fresca individual de raízes tuberosas de batata-doce. ${ }^{* *} \mathrm{p}<0,01$.

preparo do solo no armazenamento de substâncias de reserva, pois as plantas cultivadas no preparo reduzido, mesmo apresentando menor quantidade de raízes tuberosas por indivíduo que aquelas cultivadas no preparo convencional, não produziram raízes com maior massa de matéria fresca individual que no preparo convencional, ou seja, o armazenamento de substâncias de reserva por planta no preparo reduzido é menor.

A massa média de matéria fresca individual de raízes tuberosas apresentou diferença estatística apenas em função da época de coleta. O acréscimo de massa fresca individual de raiz apresentou resposta segundo modelo linear, partindo de massa estimada de $0,15 \mathrm{~kg}$ aos 90 DAP e atingindo cerca de $0,26 \mathrm{~kg}$ aos 180 DAP.

\section{CONCLUSÃO}

O preparo convencional do solo é mais adequado ao cultivo da batata-doce que o preparo reduzido, por promover maior produtividade da cultura.

\section{AGRADECIMENTO}

À Coordenação de Aperfeiçoamento de Pessoal de Nível Superior (CAPES), pela concessáo de bolsa de doutoramento à primeira autora.

\section{REFERÊNCIAS}

AGBEDE, T.M. Effect of tillage on soil properties and yam yield on an Alfisol in southwestern Nigeria. Soil \& Tillage Research, v.86, p.18, 2006. DOI: $10.1016 /$ j.still.2005.01.012

AGBEDE, T.M. Nutrient availability and cocoyam yield under different tillage practices. Soil \& Tillage Research, v.99, p.49-57, 2008. DOI: 10.1016/j.still.2007.12.003
AGBEDE, T.M. Tillage and fertilizer effects on some soil properties, leaf nutrient concentrations, growth and sweet potato yield on an Alfisol in southwestern Nigeria. Soil \& Tillage Research, v.101, p.2535, 2010. DOI: $10.1016 /$ j.still.2010.06.003

AGBEDE, T.M.; ADEKIYA, A.O. Tillage effects on soil properties and performance of sweet potato on an Alfisol in Southwestern Nigeria. American-Eurasian Journal of Sustainable Agriculture, v.3, p.561-568, 2009.

AIYELARI, E.A.; NDAEYO, U.N.; AGBOOLA, A.A. Effects of tillage practices on growth and yield of cassava (Manihot esculenta) and some soil properties in Ajibode, South-western Nigeria. Indian Journal of Agricultural Sciences, v.71, p.171-176, 2001.

ALVA, A.K.; COLLINS, H.P.; BOYDSTON, R.A. Nitrogen management for irrigated potato production under conventional and reduced tillage. Soil Science Society of America Journal, v.73, p.1496-1503, 2009. DOI: 10.2136/sssaj2008.0144

ANIKWE, M.A.N.; UBOCHI, J.N. Short-term changes in soil properties under tillage systems and their effect on sweet potato (Ipomea batatas L.) growth and yield in an Ultisol in south-eastern Nigeria. Soil Research, v.45, p.351-358, 2007. DOI: 10.1071/ SR07035

BARRERA, P. Batata-doce: uma das doze mais importantes culturas do mundo. São Paulo: Ícone, 1986. 91p.

CARTER, M.R.; SANDERSON, J.B.; PETERS, R.D. Long-term conservation tillage in potato rotations in Atlantic Canada: potato productivity, tuber quality and nutrient content. Canadian Journal of Plant Science, v.89, p.273-280, 2009. DOI: 10.4141/CJPS08073

FABRIZZI, K.P.; GARCÍA, F.O.; COSTA, J.L.; PICONE, L.I. Soil water dynamics, physical properties and corn and wheat responses to minimum and no-tillage systems in the southern Pampas of Argentina. Soil \& Tillage Research, v.81, p.57-69, 2005. DOI: 10.1016/j.still.2004.05.001

FERNANDES, H.C.; OLIVEIRA, A.D.; FONTES, P.C.R.; CAMILO, A.J.; RINALDI, P.C.N. Avaliação da cultura da batata instalada por uma plantadora adaptada para trabalhar em sistemas de plantio direto e cultivo mínimo. Ceres, v.53, p.65-73, 2006.

FONTES, P.C.R.; NUNES, J.C.S.; FERNANDES, H.C.; ARAÚJO, E.F. Características físicas do solo e produtividade da batata dependendo de sistemas de preparo do solo. Horticultura Brasileira, v.25, p.355-359, 2007. DOI: 10.1590/S0102-05362007000300007

GABRIEL FILHO, A.; PESSOA, A.C.S.; STROHHAECKER, J.; HELMICH, J.J. Preparo convencional e cultivo mínimo do solo na cultura de mandioca em condiçóes de adubação verde com ervilhaca e aveia preta. Ciência Rural, v.30, p.953-957, 2000. DOI: 10.1590/ S0103-84782000000600005

GORDON, R.J.; VANDERZAAG, A.C.; DE HAAN, R.; MADANI, A. Impact of modified tillage on runoff and nutrient loads from potato fields in Prince Edward Island. Agricultural Water Management, v.98, p.1782-1788, 2011. DOI: 10.1016/j. agwat.2011.07.007 
HOLMSTROM, D.; ARSENAULT, W.; SANDERSON, J.B.; IVANY, J. Effect of pre-plant tillage systems for potatoes in Prince Edward Island, Canada, on soil properties, weed control and potato yield. Journal of Soil and Water Conservation, v.61, p.370-380, 2006.

HOWELER, R.H.; EZUMAH, H.C.; MIDMORE, D.J. Tillage systems for root and tuber crops in the tropics. Soil \& Tillage Research, v.27, p.210-240, 1993. DOI: 10.1016/0167-1987(93)90069-2

IVANY, J.A.; ARSENAULT, W.; HOLMSTROM, D. Response of potatoes to reduced tillage and different nitrogen fertility levels. Canadian Journal of Plant Science, v.87, p.985-988, 2007. DOI: 10.4141/CJPS07011

LLANILLO, R.F.; RICHART, A.; TAVARES FILHO, J.; GUIMARÃES, M.F.; FERREIRA, R.R.M. Evolução de propriedades físicas do solo em função dos sistemas de manejo em culturas anuais. Semina: Ciências Agrárias, v.27, p.205-220, 2006.

MARTORANO, L.G.; BERGAMASCHI, H.; DALMAGO, G.A.; FARIA, R.T.; MIELNICZUK, J.; COMIRAN, F. Indicadores $\mathrm{da}$ condição hídrica do solo com soja em plantio direto e preparo convencional. Revista Brasileira de Engenharia Agrícola e Ambiental, v.13, p.397-405, 2009. DOI: 10.1590/S141543662009000400005

NUNES, J.C.S.; FONTES, P.C.R.; ARAÚJO, E.F.; SEDIYAMA, C. Potato plant growth and macronutrient uptake as affected by soil tillage and irrigation systems. Pesquisa Agropecuária Brasileira, v.41, p.1787-1792, 2006. DOI: 10.1590/S0100-204X2006001200014

ODJUGO, P.A.O. The impact of tillage systems on soil microclimate, growth and yield of cassava (Manihot utilisima) in Midwestern Nigeria. African Journal of Agricultural Research, v.3, p.225-233, 2008.

OLIVEIRA, F.L.; RIBEIRO, R.L.D.; SILVA, V.V.; GUERRA, J.G.M.; ALMEIDA, D.L. Desempenho do inhame (taro) em plantio direto e no consórcio com crotalária, sob manejo orgânico. Horticultura Brasileira, v.22, p.638-641, 2004. DOI: 10.1590/ S0102-05362004000300028
OLIVEIRA, J.O.A.P;; VIDIGAL FILHO, P.S.; TORMENA, C.A.; PEQUENO, M.G.; SCAPIM, C.A.; MUNIZ, A.S.; SAGRILO, E. Influência de sistemas de preparo do solo na produtividade da mandioca (Manihot esculenta Crantz). Revista Brasileira de Ciência do Solo, v.25, p.443-450, 2001.

OTSUBO, A.A.; MERCANTE, F.M.; SILVA, R.F.; BORGES, C.D. Sistemas de preparo do solo, plantas de cobertura e produtividade da cultura da mandioca. Pesquisa Agropecuária Brasileira, v.43, p.327332, 2008. DOI: 10.1590/S0100-204X2008000300006

PEQUENO, M.G.; VIDIGAL FILHO, P.S.; TORMENA, C.; KVITSCHAL, M.V.; MANZOTTI, M. Efeito do sistema de preparo do solo sobre características agronômicas da mandioca (Manihot esculenta Crantz). Revista Brasileira de Engenharia Agrícola e Ambiental, v.11, p.476-481, 2007. DOI: 10.1590/S141543662007000500005

QIN, R.J.; STAMP, P.; RICHNER, W. Impact of tillage and banded starter fertilizer on maize root in the top 25 centimeters of the soil. Agronomy Journal, v.97, p.674-683, 2005. DOI: 10.2134/ agronj2004.0059

RÓS, A.B.; TAVARES FILHO, J.; BARBOSA, G.M.C. Propriedades físicas de solo e crescimento de batata-doce em diferentes sistemas de preparo. Revista Brasileira de Ciência do Solo, v.37, p.242-250, 2013. DOI: 10.1590/S0100-06832013000100025

TAVARES FILHO, J.; BARBOSA, G.M.C.; GUIMARÃES, M.F.; FONSECA, I.C.B. Resistência do soloà penetração e desenvolvimento do sistema radicular do milho (Zea mays) sob diferentes sistemas de manejo em um Latossolo Roxo. Revista Brasileira de Ciência do Solo, v. 25, p.725-730, 2001.

WATANABE, S.H.; TORMENA, C.A.; ARAÚJO, M.A.; VIDIGAL FILHO, P.S.; PINTRO, J.C.; COSTA, A.C.S.; MUNIZ, A.S. Propriedades físicas de um Latossolo Vermelho Distrófico influenciadas por sistemas de preparo do solo utilizados para implantação da cultura da mandioca. Acta Scientiarum Agronomy, v.24, p.1255-1264, 2002. 